\title{
Cost-Benefit Analysis and the Knowledge Problem
}

\section{Citation}

Cass R. Sunstein, Cost-Benefit Analysis and the Knowledge Problem (Oct. 12, 2014).

\section{Permanent link}

http://nrs.harvard.edu/urn-3:HUL.InstRepos:16152306

\section{Terms of Use}

This article was downloaded from Harvard University's DASH repository, and is made available under the terms and conditions applicable to Open Access Policy Articles, as set forth at http:// nrs.harvard.edu/urn-3:HUL.InstRepos:dash.current.terms-of-use\#OAP

\section{Share Your Story}

The Harvard community has made this article openly available.

Please share how this access benefits you. Submit a story.

Accessibility 


\title{
Preliminary draft 10/10/2014 \\ All rights reserved
}

\section{Cost-Benefit Analysis and the Knowledge Problem}

\author{
Cass R. Sunstein*
}

\begin{abstract}
In the modern regulatory state, there is a serious tension between two indispensable ideas. The first is that it is important to measure, both in advance and on a continuing basis, the effects of regulation on social welfare, usually through cost-benefit analysis. The second idea, attributable above all to Friedrich Hayek, is that knowledge is widely dispersed in society. As Hayek and his followers emphasize, governments planners cannot possibly know what individuals know, simply because they lack that dispersed knowledge. When important information is missing, cost-benefit analysis can be exceptionally difficult to conduct. There are three ways to respond to that problem. The first involves notice-and-comment rulemaking, which has particular promise in the modern era, where regulators are in a far better position to collect the dispersed information of the public. The second involves retrospective analysis, accompanied by a process for obtaining public comment. In many cases, retrospective analysis has found that the ex ante estimates were wrong, thus pointing the way toward potential improvements both in rules and in future estimates. The third, and potentially the most valuable, involves experiments, above all randomized controlled trials, which can give a clear understanding of the likely effects of regulations.
\end{abstract}

\section{Two Indispensable Ideas}

With respect to the past and future of regulation, there are two truly indispensable ideas. Unfortunately, they are in serious tension with one another. Potential solutions lie in three reforms, all connected with democracy itself - but perhaps not quite in the way that most people think.

The first indispensable idea is that it is immensely important to measure, both in advance and on a continuing basis, the effects of regulation of social welfare. As an empirical matter, what are the human consequences of regulatory requirements? That is the right question to ask, but inside and outside of

\footnotetext{
* Robert Walmsley University Professor, Harvard University. This essay is a revised and greatly expanded version of Democratizing Regulation, Digitally, which appeared in Democracy: A Journal of Ideas (2014). Many thanks to the editors for permission to build on that essay here. Special thanks to Tyler Cowen and Adrian Vermeule for valuable comments on a previous draft.
} 
government, it is tempting to focus on other things. These include the opinions of relevant officials and interests ("what does the business community think?" or "do environmentalists feel strongly?"), or purely symbolic or expressive considerations, as in the unhelpful and potentially damaging view that more stringent environmental regulation, an increase in the minimum wage, or strengthened protection of occupational safety is desirable because "it makes a statement."

At the present time, the right way to answer the right question is to try to identify the costs and benefits of regulations, in order to catalogue and to compare the various consequences, and to help make sensible tradeoffs. To be sure, costbenefit analysis can create serious challenges, and at the present time, it is hardly a perfect tool. Nonetheless, it is the best one we now have. ${ }^{1}$ Some people do not love cost-benefit analysis, but they should. If we want to know about the real-world effects of regulation, that form of analysis deserves a lot of love.

The second idea, attributable above all to Friedrich Hayek, is that knowledge is widely dispersed in society. ${ }^{2}$ As Hayek and his followers emphasize, governments planners cannot possibly know what individuals know, simply because they lack that dispersed knowledge. The multiple failures of plans, and the omnipresence of unintended consequences, can be attributed, in large part, to the absence of relevant information. ${ }^{3}$ Hayek was particularly concerned about socialist-style planning. He contended that even ifs socialist planners are well-motivated and if the public interest is their true concern, they will fail, because they will not know enough to succeed. Hayek celebrated the price system as a "marvel," not for any mystical reason, but because it can aggregate dispersed information, and do so in a way that permits rapid adjustment to changing circumstances, values, and tastes.

Hayek's concern offers a serious cautionary note for planners of all kinds, including contemporary regulators who are committed, at least as a general rule, to free markets and freedom of contract. Even if they despise socialism and are simply correcting market failures (as, for example, in the domains of pollution, health care, or occupational safety), they might well lack indispensable information. Suppose that they are seeking to reduce levels of particulate matter in the ambient air. What, precisely, are the health benefits of a reduction of existing levels to 12 parts per billion (ppb), or $11 \mathrm{ppb}$, or $8 \mathrm{ppb}^{4}$ ? And what would be the costs, economic and otherwise, of mandating such reductions? When should reductions be required?

${ }^{1}$ See Cass R. Sunstein, Valuing Life: Humanizing the Regulatory State (2014). For criticism and an interesting alternative, see John Bronsteen et al., Happiness and the Law (forthcoming 2014).

${ }^{2}$ See Friedrich Hayek, The Uses of Knowledge in Society, 35 Am. Econ. Rev. 519 (1945).

${ }^{3}$ See Dietrich Dorner, The Logic of Failure (1996)

${ }^{4}$ On some of the challenges here, see Francesca Dominici et al., Particulate Matter Matters, 244 Science 257 (2014). 
How should they be obtained? Should small businesses receive exemptions? Of what kinds? What are the alternative approaches, and of these, which is best?

The problem should not be overstated. With respect to costs, regulators often have a good sense of potential outcomes, in part because of information from the regulated sector. To be sure, that information might well be self-serving, but regulators often have sufficient experience to discount alarmist or excessive claims. With respect to benefits, quantification and monetization present separate issues. In many domains, existing knowledge is sufficient to permit the identification of sufficiently narrow ranges with respect to (say) mortalities averted or accidents prevented. ${ }^{5}$ Well-established (and continuously improving) tools are in place to convert various values into monetary equivalents. ${ }^{6}$ In the day-to-day life of costbenefit analysis, regulators are hardly making a stab in the dark. Usually they have, or are able to accumulate, a great deal of relevant information.

Nonetheless, modern followers of Hayek are correct to emphasize what they call "the knowledge problem," understood as the government's potential ignorance, which can be a problem for contemporary regulators of all kinds, working (for example) to implement the Clean Air Act, the Occupational Safety and Health Act, the Affordable Care Act, and the Dodd-Frank Wall Street Reform and Consumer Protection Act. If cost-benefit analysis is essential to sensible judgments, incomplete knowledge, when it exists, would appear to be a serious and potentially devastating problem. In some cases, agencies do face serious challenges in cataloguing costs and benefits. ${ }^{7}$ Retrospective analysis attests to those challenges, because it has identified a number of mistakes. ${ }^{8}$

The tension, in short, is that regulators have to focus on costs and benefits (the first indispensable idea), but they will sometimes lack the information that would enable them to make accurate assessments (the second indispensable idea). In light of the knowledge problem, can they produce reliable cost-benefit analyses, or any other kind of projection of the human consequences of what they seek to do, and of potential alternatives? What I am urging, in short, is that regulators are in large part technocrats, charged with measuring and assessing consequences, but

${ }^{5}$ See Cass R. Sunstein, The Real World of Cost-Benefit Analysis, 114 Colum L Rev 167 (2014).

${ }^{6}$ See OMB Circular A-4, available at http://www.whitehouse.gov/omb/circulars_a004_a-4

${ }^{7}$ For an emphasis on this point, see John Coates, Cost-Benefit Analysis of Financial Regulation, Yale LJ (forthcoming 2014), available at http://papers.ssrn.com/sol3/papers.cfm?abstract_id=2375396. I do not address here the question of the judicial role in requiring cost-benefit analysis. Relevant discussion, with disagreement between the two authors, can be found in Cass R. Sunstein and Adrian Vermeule, Libertarian Administrative Law, U Chi L Rev (forthcoming 2015).

${ }^{8}$ See infra. 
their technocratic enterprise runs into a serious objection. Of course the force of the objection will depend on the context, but in some situations, the effort to assess the likely effects of a regulatory intervention (involving pollution, health care, energy, transportation safety, communications, or homeland security) might go badly wrong.

Three reforms can help. ${ }^{9}$ The first involves the process of notice-andcomment rulemaking, updated for the current era, and with a clear sense of the underlying substantive goal, which is to obtain information about the likely consequences of regulations (including costs and benefits). The second involves retrospective analysis of rules, which can both produce changes in those rules and lead to significant improvements in prospective analysis. To realize its potential, retrospective analysis should be undertaken with public comment. The third reform involves careful experiments, above all randomized controlled trials, which can provide far better information than expert judgments. ${ }^{10}$ In some ways, the third reform is the most promising, but it does present challenges in terms of feasibility.

${ }^{9}$ I am not suggesting that Hayek himself would be satisfied. Consider this remarkable passage:

This is, perhaps, also the point where I should briefly mention the fact that the sort of knowledge with which I have been concerned is knowledge of the kind which by its nature cannot enter into statistics and therefore cannot be conveyed to any central authority in statistical form. The statistics which such a central authority would have to use would have to be arrived at precisely by abstracting from minor differences between the things, by lumping together, as resources of one kind, items which differ as regards location, quality, and other particulars, in a way which may be very significant for the specific decision. It follows from this that central planning based on statistical information by its nature cannot take direct account of these circumstances of time and place and that the central planner will have to find some way or other in which the decisions depending on them can be left to the "man on the spot."'

Hayek, supra note. In my view, the claim here is a mystification, at least as applied to the regulatory context. Statistical information "by its nature" can indeed "take direct account of these circumstances of time and place." Of course it is true that for some purposes and activities, statistical knowledge is inadequate.

${ }^{10}$ Duncan Watts, Everything is Obvious (2011); Jim Manzi, Uncontrolled: The Surprising Payoff of Trial-and-Error for Business, Politics, and Society (2012); Michael Greenstone, Toward a Culture of Persistent Regulatory Experimentation and Evaluation, in NEW PERSPECTIVES ON REGULATION 113, 113 (David Moss \& John Cisterno eds., 2009). A relevant discussion, involving quasi-experimental techniques in an especially important area, is Francesca Dominici et al., Particulate Matter Matters, 244 Science 257 (2014). It is true that randomized controlled 


\section{An Old Debate}

During and after Franklin Delano Roosevelt's New Deal, the United States saw an intense debate about government regulation. ${ }^{11}$ The competing sides were the New Deal enthusiasts, receptive to the larger regulatory state, ${ }^{12}$ and the New Deal critics, insisting that the new administrative institutions were a betrayal of constitutional ideals. One of the enduring products of that debate was the Administrative Procedure Act (APA), enacted in $1946 .{ }^{13}$ The APA contained a genuine innovation, now called "notice-and-comment rulemaking." 14 The basic idea is that regulators do not merely consult with one another and then issue final rules. Instead, they must provide the public with advance notice of what they are planning to do, and why, and then they solicit comments. It was expected that when agencies finalized rules, they would incorporate what they learned from the public.

Why did Congress call for notice-and-comment rulemaking? The historical record does not give an unambiguous answer, but we can isolate two quite different factors. The first involves self-government itself. During and after the New Deal, some people have been greatly concerned that regulators are not directly accountable to the people, and have contended that they may suffer from some kind of "democracy deficit."15 In an extreme view, the result is some kind of crisis of legitimacy. ${ }^{16}$ For such critics, notice-and-comment rulemaking may not be sufficient, but it is an important way to help legitimate the administrative process, by increasing accountability and responsiveness. A kind of democratic participation is built into the very idea of notice-and-comment rulemaking. That admittedly technical idea is designed to help to ensure ultimate rule, or at least access, by We the People. If administrators are not directly accountable through elections, at least it can be said that they must listen and respond to the public insofar as its members are willing to raise objections and concerns.

The second idea is less abstract and high-flown, and it is, I think, even more important. It involves information, not legitimation, and it has roots in Hayek's concerns. ${ }^{17}$ We have seen that if government is attempting to make air cleaner or food safer, to reduce deaths in the workplace or on the highways, or to increase

experiments have been subject to some concerns. See Angus Deaton, Instruments of Development (2009), available at http://www.nber.org/papers/w14690

${ }^{11}$ See Daniel Ernst, Toqueville's Nightmare (2013), for a valuable discussion of the background.

12 The classic discussion is James Landis, The Administrative Process (1935).

135 USC 551 et seq.

145 USC 553.

${ }^{15}$ For an extreme version of this argument, see Philip Hamburger, Is Administrative Law Unlawful? (2014).

${ }^{16}$ See James O. Freedman, Crisis and Legitimacy (1980).

17 But see note supra. 
homeland security, it might well have incomplete information about the effects of its plans. Some nonhypothetical examples: If regulators are concerned to eliminate emissions of ozone-depleting chemicals, they might end up banning asthma inhalers, and such bans might have adverse effects on human health. If regulators take steps to make the food supply safer, they might impose high costs on farmers, including small farmers, and potentially create serious economics dislocations. If government imposes high costs on electricity producers, it might produce a spike in the cost of electricity, which would be particularly harmful for the poor.

To make sensible decisions, regulators need to obtain a great deal of information about questions of this kind. As hard as they might try, they will not know everything, and they may have significant gaps in their knowledge. Within government, those with technical expertise will try to fill those gaps, but their efforts might be insufficient. Here is the potential of the notice-and-comment process. If regulators have made mistakes or been too optimistic, there is a real chance that members of the public will tell them about it. ${ }^{18}$ Their own assessment of the costs of a proposed rule might depend on unrealistic assumptions..$^{19}$ If so, someone might well object on that ground. Regulators might not have seen how a well-intended rule would affect small business. Their scientific projections might not be consistent with recent scientific findings. They might have neglected local circumstances, falling to understand that makes sense in Los Angeles and New York is unnecessary or even harmful in Carson City and Boise. They might have missed the potential effects of a low-cost technology. They might not have appreciated the possibility that another approach would have higher net benefits. ${ }^{20}$

On this view, the most important goal of notice-and-comment rulemaking is to increase the likelihood that agencies will obtain relevant information. Some of that information might come from technical specialists outside of government, who can correct agency errors (about, for example, the carcinogenic properties of silica, the social cost of carbon, or the likely costs of emissions controls). Some of it might come from private associations with distinctive knowledge of particular sectors. Some of it might come from people with highly localized knowledge, which might escape the regulators' attention. If the knowledge problem cannot always be eliminated - and it would be foolish to think that it can be - at least it can be reduced, in part through institutions that increase the likelihood that public officials will learn from what members of the public know.

\footnotetext{
18 For a prominent example, see https://www.osha.gov/pls/oshaweb/owadisp.show_document?p_table=NEWS_REL EASES\&p_id=19119

19 Id.

${ }^{20}$ For an example, see http://water.epa.gov/scitech/wastetech/guide/airport/upload/airport_prepub.pdf; http://www.cryotech.com/epa-releases-ruling-on-effluent-limitations-for-airportscryotech-pavement-deicers-comply
} 
It is important to emphasize that the notice-and-comment process is not the only way for agencies to obtain dispersed knowledge. Regulators often engage in extensive consultations before rules are even proposed - sometimes through informal routes, sometimes through formal "requests for information" (published in the Federal Register), sometimes through advance notices of proposed rulemaking. All of these strategies are indispensable. Executive Order 13563 goes so far as to state, "Before issuing a notice of proposed rulemaking, each agency, where feasible and appropriate, shall seek the views of those who are likely to be affected, including those who are likely to benefit from and those who are potentially subject to such rulemaking." 21 The various forms of information-gathering - preliminary to proposed rulemaking - can be essential to accurate cost-benefit analysis.

\section{Unrealized Potential}

In the initial decades after enactment of the APA, some people greatly admired the notice-and-comment process, celebrating its immense potential for providing valuable information. But it did not realize that potential. There were two reasons. The first is that for decades, many regulatory agencies relied on adjudication, rather than rulemaking, to make public policy. Instead of proposing a new regulation, for example, the Federal Trade Commission would initiate a proceeding against someone who engaged in apparently deceptive advertising, and it would produce the functional equivalent of a new rule as a result of that proceeding. Needless to say, this kind of approach - policymaking by adjudication -was far from ideal, in part because regulators would be unlikely to hear from enough people. Moreover, cost-benefit analysis does not precede or accompany the orders that emerge form adjudication. For multiple reasons, the rule-like decisions that follow adjudication might turn out to be inadequately informed. But since the 1980s, and in part for this very reason, agencies have chosen to rely far more on notice-and-comment rulemaking (with the continuing and disappointing exception

of the National Labor Relations Board, which relies on adjudication to this day ${ }^{22}$ ).

The second reason is that from the standpoint of most members of the public, the notice-and-comment process has been quite arcane - unknown and even unfathomable. It is not exactly simple to send comments to regulators, or for regulators to read and assess everything that they receive. At least part of the problem can be captured in a single word: paper. So long as everything was received and read in hard copy, there were significant limits to the notice-and-comment process. Among other things, those who sought to file comments could not necessarily or easily see the comments send by other people. For the process to work as well as it might, that kind of visibility, and a substantive back-and-forth, could be exceedingly important. There is an enduring ideal of "government by

21 Executive Order 13563, available at http://www.gpo.gov/fdsys/pkg/FR-2011-0121/pdf/2011-1385.pdf

22 For an implicit lament, see Allentown Mack Sales and Services v. NLRB, 522 US 359 (1998). 
discussion"23; that ideal cannot be realized if substantive ideas are not broadly visible.

\section{The Age of E-Rulemaking}

We have now entered the age of e-rulemaking, thanks in part to Executive Order 13563, issued by President Obama in 2011 and serving as a kind of miniConstitution for the regulatory state. (Regulations.gov is the key website.) As we shall see, that Executive Order promises to reduce the tension between the two indispensable ideas with which I began by increasing the likelihood that regulators will have access to dispersed information.

\section{A. Regulations.gov}

Among other things, Executive Order 13563 requires regulations to be adopted "through a process that involves public participation."24 It directs agencies to "afford the public a meaningful opportunity to comment through the Internet on any proposed regulation, with a comment period that should generally be at least 60 days." Importantly, it requires agencies to "provide, for both proposed and final rules, timely online access to the rulemaking docket on regulations.gov, including relevant scientific and technical findings, in an open format that can be easily searched and downloaded."

For proposed rules, that access must include an "opportunity for public comment on all pertinent parts of the rulemaking docket, including relevant scientific and technical findings." Do not be fooled by the technical jargon ("rulemaking docket") in that last sentence. It means, in essence, that members of the public are allowed to see technical support for regulations, including the analysis of costs and benefits, and also to see public comments themselves. That form of transparency is exceedingly important, because it triggers public scrutiny and generates a great deal in the way of additional information.

Regulations.gov may not be everyone's favorite website, and it is not a lot of fun, but it has transformed notice-and-comment rulemaking. When the agency proposes a rule, all the world can find it and see it, usually with great ease. Both the rule and the technical analyses are standardly available. If the proposal has a mistake, or veers in a bad direction, there is a genuine opportunity to comment and to get the problem fixed. When I served as Administrator of the White House Office of Information and Regulatory Affairs from 2009 to 2012, I was surprised by one thing above all: Many regulators pay exceedingly close attention to public comments, and they spend a lot of time on regulations.gov. Such comments are carefully read, typically by people who have the actual authority to move regulations in better directions. (Such people including officials in the rulemaking

${ }^{23}$ See Amartya Sen, The Idea of Justice (2010).

${ }^{24}$ See note supra. 
agency, in OIRA, and in various White House offices, such as the Domestic Policy Council and the National Economic Council. ${ }^{25}$ ) Very often, they do so on the basis of what they learn. For this reason, the notice-and-comment process is hardly a charade. With respect to regulation, it is a central part of agency decisionmaking.

In the modern era, regulators are in a far better position to collect the dispersed information of the public. On this view, the goal of notice-and-comment rulemaking is emphatically not to take an opinion poll, to take some kind of political temperature, to see how much applause a proposal is able to attract, to defuse public opposition, to engage in some communications strategy, or to collect the digital equivalent of postcards (even though a number of those are sometimes sent in). Instead the goal is overwhelmingly substantive - to fill gaps in knowledge and to see what might have been overlooked. In particular, the agency's assessment of the likely consequences is subject to close scrutiny. If the agency has inaccurately assessed costs and benefits, public participation can and often will supply a corrective. Democratization of the regulatory process, through the comment process, has an epistemic value. ${ }^{26}$ It helps to collect dispersed knowledge and to bring it to bear on official choices.

\section{B. The Challenge of Complexity}

It is true that many rules continue to be lengthy and complex. For the public comment process to work, they must be comprehensible rather than opaque, and technical language and sheer length can reduce comprehensibility. Executive summaries, now required for long or complex rules, can help, ${ }^{27}$ but they are not sufficient. Experiments with the idea of a "regulation room," 28 offering plain language versions of regulatory proposals, are designed to promote broader understanding, but those experiments have not been an unambiguous success. Some of the relevant comments, in those experiments, look like simple thumbs-up or thumbs-down, and because they fail to provide new information, they do not genuinely inform regulatory judgments.

To come to terms with the challenge of complex rules, it is important to distinguish between two conceptions of the purpose of the public comment process. On one conception, connected with the idea of legitimation, the goal is to allow We the People - anyone, really - to participate in the process. If so, intelligibility and clarity are indispensable, and complexity is a genuinely serious problem. On another

${ }^{25}$ See Cass R. Sunstein, The Office of Information and Regulatory Affairs: Myths and Realities, 126 Harv L Rev 1838 (2013).

${ }^{26}$ For relevant discussion, see Adrian Vermeule, Local and Global Knowledge in the Administrative State (2012), available at http://papers.ssrn.com/sol3/papers.cfm?abstract_id=2169939

27 http://www.federalregister.gov/uploads/2011/02/OIRA-clarifying-regulatoryrequirements-executive-summaries.pdf

${ }^{28}$ See http://regulationroom.org/ 
conception, connected with the epistemic idea, the goal is to allow participation by those who have relevant information to contribute. If so, intelligibility and clarity are important, but because the process typically has a large technical component, the absence of genuine "plain language" need not be a fatal flaw, so long as those who have relevant information to add are in a position to do so.

\section{Of Hubris and Risks}

It is important to acknowledge that even in its most ambitious forms, and even if we emphasize the overriding importance of substantive contributions, the public comment process might fail to solve the knowledge problem, and there are imaginable risks as well. Centralized planning, of the old-style socialist sort, could hardly be redeemed by public notice-and-comment. It is true that five-year plans would likely be improved by efforts to receive public comments, but we should not, for that reason, favor five-year plans. Dedicated followers of Hayek would urge that the process of aggregating information will inevitably be imperfect and (in their view) probably worse than that. ${ }^{29}$ Markets encode the emphatically local knowledge and values of everyone who produces or purchases relevant products. By contrast, most citizens, including many with substantive contributions to make, are unlikely to know about notice-and-comment rulemaking, or to have the commitment and background that would enable them to participate. There are strong reasons to demand a convincing demonstration of some kind of market failure before embarking on regulation..$^{30} \mathrm{An}$ even if a market failure is shown, market-friendly responses (such as disclosure of information or corrective taxes) deserve pride of place, in part because they reduce informational demands on regulators and can enlist rather than displace private knowledge.

There is an independent point. It would be possible to fear that wellorganized groups, of one of another kind, will inevitably play the' most important part in notice-and-comment rulemaking, and even to dominate it. If so, there will be a kind of epistemic "skew" on the part of regulators. The supposed solution to the knowledge problem may make things even worse. The most frequent comments, and the most competent ones, will come from those whose self-interest is at stake, thus creating a distinctive form of capture, one that is epistemic in nature.

This risk cannot be dismissed in the abstract. It may well be realized in practice. But it is also true that public officials are fully able to discount self-serving arguments, and to give critical scrutiny to external arguments and claims (often with the aid of a wide array of public comments). During my period in government, I witnessed this process every day. Within the executive branch, people work exceedingly hard to produce solutions that are sensible, whether or not particular interest groups like them. Insofar as diverse regulators are working together to produce lawful regulations, justified by costs and benefits, members of the public,

${ }^{29}$ See note supra.

30 See id. 
the media, and academic observers wildly overstate the role of interest groups and even of political pressures. For regulators, the principal problem is not such pressures; it is a lack of information. ${ }^{31}$ On that count, notice-and-comment rulemaking turns out to be crucial.

In the coming decades, the ability to elicit and compile information will inevitably expand at an extraordinarily rapid rate. A pressing question is how to use that information to reduce the risks of regulatory error, not least with respect to cost-benefit analysis itself. We could easily imagine large-scale improvements on this count as massive data sets become increasingly simple to compile and analyze. In the fullness of time, notice-and-comment rulemaking will become, far more than it is today, a major contributor to forms of data acquisition that are indispensable to accurate cost-benefit analysis.

\section{Retrospective Analysis}

Agency rulemaking occurs before the fact, when information-gathering is highly likely to be imperfect. ${ }^{32} \mathrm{~A}$ sensible regulatory system gives continuing scrutiny to regulatory requirements to test whether they are working as anticipated. A central question is whether the ex ante estimates square with what is known ex post. If they do not, regulations can be changed. There is another advantage to retrospective analysis: It can help to inform and improve prospective analysis, as agencies learn about their own mistakes, and can become less likely to make them in the future. In this respect, retrospective analysis can help to reform prospective analysis.

On these counts, existing knowledge remains incomplete, but some valuable research can be found. Consider, for example, Winston Harrington's careful study. ${ }^{33}$ Building on previous work, Harrington explored sixty-one rules for which benefitcost ratios could be compared before and after the fact. He found significant errors but no systematic bias. In his account, agencies overestimated both benefits and costs with about equal frequency. Specifically, in sixteen of the sixty-one cases, the ratios were found to be essentially accurate. In twenty-four cases, the ratio was better, not worse, than the agency had anticipated. In twenty-one cases, the ratio was worse than anticipated. Harrington's general conclusion is that while both costs

31 My own experience suggests that academics wildly overstate the public choice problem, at least as it operates within the executive branch. But they do not overstate, and may even understate, the knowledge problem.

32 The point is emphasized in Greenstone, supra note. I draw in this section and in the following on Cass R. Sunstein, Simpler (2013) and Cass R. Sunstein, The Regulatory Lookback, 94 B.U. L. Rev. 579 (2014).

33 Winston Harrington, Grading Estimates of the Benefits and Costs of Federal Regulation (Res. for the Future, Paper No. 06-39, 2006), available at http://papers.ssrn.com/sol3/papers.cfm?abstract_id=937357. 
and benefits tend to be lower than estimated, no bias can be found in estimates of benefit-cost ratios.

While highly illuminating, Harrington's study leaves many questions unanswered. The same size is exceedingly small. Harrington focuses on benefit-cost ratios, which is certainly a relevant question but not the central one. What most matters is net benefits and whether agencies have accurately calculated them. Nor does Harrington specify the degree to which benefits and costs were underestimated or overestimated. Other studies do explore the question of underestimation or overestimation. One such study analyzed twenty-one environmental and occupational safety regulations for which retrospective estimates could be found ${ }^{34}$ The basic conclusion is that agencies display a modest tendency to overestimate costs. For thirteen rules, agencies overestimated costs; they estimated costs accurately for four; they underestimated for three; and the costs were indeterminate for one.

In 2005, the Office of Management and Budget, and in particular the Office of Information and Regulatory Affairs, provided an overview of many retrospective analyses based on an examination of forty-seven case studies. ${ }^{35} \mathrm{~A}$ particular concern was the risk that ex ante estimates might be inadequately informed and therefore erroneous. The overview offers three key conclusions. First, agencies were far more likely to overestimate benefits than to underestimate them. More particularly, agencies overestimated benefits forty percent of the time, whereas they underestimated benefits only two percent of the time. Second, agencies tended to overestimate the benefit-cost ratio, and in that sense to be a bit too optimistic about the consequences of their rules. Agency estimates were accurate twenty-three percent of the time, while the ratio was overestimated forty-seven percent of the time and underestimated thirty percent of the time. Third, agencies were slightly more likely to overestimate than to underestimate costs. Agencies were accurate twenty-six percent of the time, overestimated costs thirty-four percent of the time, and underestimated costs twenty-six percent of the time.

From existing work, the most sensible general conclusion is that agencies do make many mistakes (attesting to the reality of the knowledge problem), but there does not appear to be a systematic bias in any one direction. That is useful and

34 Winston Harrington et al., On the Accuracy of Regulatory Cost Estimates, $19 \mathrm{~J}$. POL'Y ANALYSIS \& MGMT. 297 (2000).

35 See See OfFice of Mgmt. \& Budget, Validating Regulatory Analysis: 2005 Report to Congress on the Costs and Benefits of Federal Regulations and Unfunded MANDATES ON STATE, LOCAL, AND TRIBAL ENTiTies 41-46 (2005), available at http://www.whitehouse.gov/sites/default/files/omb/assets/omb/inforeg/2005_cb /final_2005_cb_report.pdf (collecting studies comparing ex ante and ex post analyses of regulations' costs and benefits, including examples where cost and benefit estimates were off by more than a factor of ten). 
important to know. But it is even more important to acknowledge that we need to know a great deal more than we now do. The existing studies cover only a trivially small fraction of rules on the books. Much more can and should be done to compare prospective estimates to what actually happens in the world.

\section{B. Retrospective Analysis, With Public Comment}

In 2011, President Obama issued Executive Order 13,563, which requires retrospective analysis of existing rules. A key goal is to reduce the knowledge problem, not by assembling information in advance, but by bringing to bear information about how rules are actually operating, and with explicit reference to the dispersed information of the public.

After the order was issued, the initial step was the production of preliminary plans for retrospective review, which were required within 120 days. This was an aggressive timeline, especially considering the fact that public officials have numerous responsibilities. Many agencies began by asking for suggestions from the public, requesting ideas about which regulations must needed to be revisited. For example, the Environmental Protection Agency and the Departments of Commerce, Transportation, Interior, Homeland Security, State, and Treasury posted notices in the Federal Register, asking for comments about how the process should work and which rules should be streamlined or repealed. Several agencies held public meetings nationwide.

A small subset of these initiatives, finalized or formally proposed to the public, is producing savings of more than $\$ 10$ billion in a short period. Many of the resulting initiatives also provide benefits that are hard to monetize but likely to be significant. For example, it is not easy to quantify the economic benefits, including the jobs created, of reducing restrictions on exports and simplifying the requirements imposed on those who do business across national borders. Nonetheless, those benefits are expected to be high.

In 2012, President Obama issued a supplemental Executive Order with three key components. ${ }^{36}$ First, agencies are required to reach out to the public, on a continuing basis, to solicit ideas about reforms. Second, agencies must give priority to reforms that would have a significant impact - for example, those with substantial economic savings. New initiatives should make a real difference; they should not be symbolic measures or mere updating. Third, and perhaps most important, agencies have to report on their progress to OIRA and to the public on a continuing basis. This final step is designed to promote accountability - to ensure that if agencies are not doing much, the public will be able to see that and provide a corrective. In all of these ways, the process of retrospective analysis is expected to be informed by the

36 Exec. Order No. 13,610, 3 C.F.R. 258 (2012), reprinted in 5 U.S.C. § 601 at 820-21 (2012). 
dispersed information of the public.

\section{Experiments}

To get the facts right, it is important to engage in far more evaluation and experimentation. The central goal is not to rely even on expert judgments about likely effects, but instead to compile evidence from the real world. ${ }^{37}$ In the past decade, there has been growing interest in the use of randomized controlled trials as a means of learning the effects of policy initiatives. ${ }^{38}$ In medicine, of course, it is standard to rely on such trials to see if a drug is safe and effective. For drugs, it would not make a great deal of sense simply to guess, to rely on informed hunches, or even to make simple "before and after" assessments. Suppose that we learn that people who use a certain asthma medicine do better after taking the medicine than before. If so, we know something important-but we do not know nearly enough. The risk with before-and-after assessments is that they may not control for confounding variables. Perhaps people are doing better because of some change in the environment that is not adequately understood by those who are making the assessment. In the medical domain, the value of randomized controlled experiments is that they have the potential to provide a clear sense of the actual effects of the intervention.

Esther Duflo, along with many others, has pioneered the use of randomized controlled trials for purposes of policy evaluation. ${ }^{39}$ In principle, such trials are the best way to solve the knowledge problem; they provide the closest thing to the gold standard, and in at least in some context, they should adequately respond to the Hayekian concern. ${ }^{40}$ Duflo has shown that in many cases, small measures can have significant effects. In the regulatory area, the use of such trials remains in a preliminary state ${ }^{41}$ Analysis of costs and benefits is rarely informed by them. But it is easy to imagine serious evaluations. ${ }^{42}$ Consider a few examples:

-- Would state regulators save lives by banning the use of cell phones while driving? This is a disputed question. Laboratory experiments, showing that people's reaction times slow down when they are distracted, strongly suggest that the answer is affirmative, and indeed that driving while talking on a phone is not unlike driving while inebriated, producing a fourfold increase in relative crash

37 See Dominici et al., supra note.

${ }^{38}$ See note supra.

${ }^{39}$ See generally ABHIJIT BANERJEE \& ESTHER DUFLO, POOR ECONOMICS (2011).

${ }^{40}$ See Dominici et al., supra note. For skeptical remarks, see Deaton, supra note.

${ }^{41}$ For valuable discussion, see Michael Abramowicz, Predictocracy (2008); Michael

Abramwicz et al., Randomizing Law (2010), available at

http://papers.ssrn.com/sol3/papers.cfm?abstract_id=1672057

${ }^{42}$ See Abramowicz, supra note. 
risk. ${ }^{43}$ But perhaps those experiments are an unreliable guide to the real world. We could test whether a ban on cell phone use would have major effects on safety by comparing similarly situated localities, one with such a ban and one without. Or we could test whether accidents increase in periods in which cell phone use goes up - for example, when rates decrease after 9 p.m. (In fact precisely that question has been studied, with a surprising finding of no such increase. ${ }^{44}$ )

-- What are the effects of different methods of increasing rear visibility in cars? If cameras are placed in the dashboard, do accidents drop? How much, and compared to what? Do improved mirrors have a significant effect? What about sonar devices, making beeping noises? Do they work as well as cameras? Randomized trials might help (assuming that sufficiently large sample sizes could be obtained).

-- It is important to evaluate different disclosure requirements. ${ }^{45}$ We might test whether different fuel economy labels have different effects on similarly situated consumers. Does one label produce different choices? How different? If labels draw attention to annual fuel costs, are people affected? Do people care about environmental factors? How much? The same kinds of questions might be asked about disclosure requirements for credit cards, mortgages, cell phones, and school loans.

In important areas, experimentation might take the form of advance testing of regulatory alternatives through randomized controlled trials. A movement in this direction would have major advantages over current approaches, such as focus groups, which are often highly artificial and which sometimes test what people like rather than what they would actually do. A presentation might be pleasing without having much of an effect on what people understand and do.

In the United Kingdom, there has been a great deal of interest in using randomized controlled trials, above all through the work of the Behavioral Insights Team (sometimes called the Nudge Unit). ${ }^{46}$ Related efforts are being made in the United States and elsewhere. If randomized trials are not feasible, we might be able to design experiments that replicate actual behavior by asking people concrete

43 CHARLOTTE L. BRACE ET AL., ANALYSIS OF THE LITERATURE: THE USE OF MOBILE PHONES WHILE DRIVING (2007), available at http://www.nsc.org/news_resources/Resources/Documents/Analysis\%20of\%20th e\%20Literature, \%20The\%20Use\%20of\%20Mobile\%20Phones\%20While\%20Driving.pdf.

44 Saurabh Bhargava \& Vikram Pathania, Driving Under the (Cellular) Influence: The Link Between Cell Phone Use and Vehicle Crashes 5 AM. ECON. J.: ECON. POLICY 92, available at http://pubs.aeaweb.org/doi/pdfplus/10.1257/pol.5.3.92.

45 See George Lowenstein et al., Disclosure: Psychology Changes Everything, 6 Annual Review of Economics 391 (2014).

46 https://www.gov.uk/government/organisations/behavioural-insights-team 
questions about what they would do if provided with certain information or if given a range of options.

Of course there are constraints-involving not merely law but also resources and feasibility (and perhaps equity as well) -in using randomized controlled trials in the regulatory context. Among other things, sufficient sample sizes might be difficult to obtain. But in some cases, they would be both appropriate and useful. The agencies' retrospective review plans show an unambiguous commitment to moving in this direction. The Department of Treasury states that it will work to "develop and incorporate experimental designs into retrospective analysis, when appropriate." 47 The Department of Labor states that it "is contemplating how to incorporate the use of experimental designs to determine the impact of various regulations." 48 The Department of Interior states that it will consider the use of "experimental or quasi-experimental designs, including randomized controlled trials." 49 We should expect far more progress in the future.

\section{Conclusion}

There can be a serious tension between the commitment to cost-benefit analysis and a realistic appreciation of the limits of official knowledge. Without

\footnotetext{
${ }^{47}$ DEP'T OF THE TREASURY, PLAN FOR RETROSPECTIVE ANALYSIS OF EXISTING RULES 20 (2011), available at http://www.treasury.gov/about/budget-performance/annualperformanceplan/ Documents/lookback\%20plan\%20final\%208\%2018\%2011\%20clean.pdf. 48 U.S. DEP'T OF LABOR, PRELIMINARY PLAN FOR RETROSPECTIVE ANALYSIS OF EXISTING

RULES 22 (2011), available at http://www.whitehouse.gov/files/documents/2011regulatoryactionplans/DepartmentofLaborPreliminaryRegulatoryReformPlan.pdf.

${ }^{49}$ DEP'T OF THE INTERIOR, PRELIMINARY PLAN FOR RETROSPECTIVE REGULATORY REVIEW 19, available at http://www.whitehouse.gov/files/documents/2011-regulatoryactionplans/ DepartmentoftheInteriorPreliminaryRegulatoryReformPlan.pdf. See also U.S. DEP'T OF
}

AGRICULTURE, FINAL PLAN FOR RETROSPECTIVE ANALYSIS PURSUANT TO EXECUTIVE ORDER

13563, at 23 (2011), available at http://www.whitehouse.gov/sites/default/files/other/2011regulatory-action plans/departmentofagricultureregulatoryreformplanaugust2011.pdf ("[The USDA] may consider the use of experimental or quasi-experimental designs, including randomized controlled trials, when promoting the empirical testing of the effects of rules."). 
significant efforts to reduce those limits, such analysis might be inadequately informed. Whenever regulators face significant informational deficits, it is important to explore tools that take advantage of what the private sector knows; marketfriendly tools, such as economic incentives, have important advantages on that count. In some cases, regulators might appropriately decide to abstain entirely on the ground that the market failure is not clear and any cure might be worse than the disease.

In other cases, however, Congress has required agencies to act, or the argument for action is too powerful to be ignored. In such cases, cost-benefit analysis is often indispensable. As a result of modern technologies, the old tool of notice-and-comment rulemaking has new promise in acquiring dispersed information. This point holds not only for new rules, which lack a track record, but also for retrospective analysis of old rules, for which the private sector often has important information about both costs and benefits. It would be extravagant to contend that notice-and-comment rulemaking can eliminate the knowledge problem, even in the modern era, but it can produce a great deal of help. When combined with retrospective analysis of regulations - itself spurred and informed by public comment -- and with experimental evidence, it might well be possible to reduce the enduring tension between two ideas that belong at the heart of contemporary thinking about the administrative state. 
